\title{
Calorimetric study of solid state reactions
}

\author{
K. Feder, K. Gance and E. J. Cotts \\ Physics Department, Binghamton University, Binghamton, NY 13902
}

\begin{abstract}
We examine the effects of atomic mobility on solid state amorphization reactions by comparing reactions in $\mathrm{Ni} / \mathrm{Zr}_{\mathrm{x}} \mathrm{Ti}_{1-\mathrm{x}}$ composites as the $\mathrm{Zr}$ concentration, $\mathrm{x}$, is varied. $\mathrm{X}$-ray diffraction and differential scanning calorimetry are utilized to study the growth of amorphous phases. Differences in solid state reactions in these systems can be attributed to the size difference in the $\mathrm{Zr}$ and $\mathrm{Ti}$ atoms, and resulting variations in atomic mobilities. At low temperatures $(300 \mathrm{~K}<\mathrm{T}<650 \mathrm{~K})$ in the $\mathrm{Ni}-\mathrm{Zr}_{\mathrm{x}} \mathrm{Ti}_{1-\mathrm{x}}$ system we observe a direct dependence of the rate of solid state reaction on $\mathrm{Zr}$ concentration.
\end{abstract}

\section{INTRODUCTION}

Single phase amorphous alloys can form in diffusion couples at relatively low temperatures (approximately half pertinent melting temperatures) by means of interdiffusion of pure, polycrystalline elements (refs. 1-12). Amorphous layers of thickness of up to $100 \mathrm{~nm}$ have been grown in a number of different systems, including $\mathrm{Ni}-\mathrm{Zr}$ and $\mathrm{Rh}-\mathrm{Si}$, by means of these solid state amorphization reactions. A number of requirements have been proposed for the formation of amorphous alloys in diffusion couples by means of solid state reaction (refs. 1-3). The two metals which form the diffusion couple must possess a large, negative heat of mixing in the amorphous phase in order to drive the reaction. There must be a dominant moving species, $\dot{i}$. e. one constituent of the diffusion couple should exhibit a much greater mobility than the other. The movement of both constituents is apparently required to nucleate and grow crystalline material while the mobility of only one constituent is required to grow an amorphous alloy. Such a disparity in the mobility of the atoms in the diffusion couple provides a constraint on the formation of equilibrium intermetallic compounds in a given temperature range and time frame, $i$. e. a kinetic constraint. It has also been indicated that initially, in the as-prepared composite, a certain degree of disorder present at the interface between the polycrystalline metals facilitates the growth of amorphous material (ref. 8). Without such disorder at the interface, the nucleation and growth of equilibrium intermetallic compounds may be favored.

The present study concerns a comparison of solid state reactions in $\mathrm{Ni} / \mathrm{Zr}_{\mathbf{x}} \mathrm{Ti}_{1-\mathrm{x}}$ diffusion couples with different $\mathrm{Zr}$ concentrations. Solid state amorphization reactions have been previously observed to occur in both the $\mathrm{Ni}-\mathrm{Zr}$ and the $\mathrm{Ni}-\mathrm{Ti}$ systems (ref. 12), but it is the differences between these solid state amorphization reactions which reveal some information relevant to an understanding of the micromechanisms of these reactions. As both $\mathrm{Zr}$ and $\mathrm{Ti}$ are IVA elements, these elements would be expected to display chemical similarities. In fact, it is observed that at room temperature $\mathrm{Zr}$ and $\mathrm{Ti}$ form a solid substitutional, hexagonal close packed (hcp) alloy for all $\mathrm{Zr}$ concentrations. No equilibrium compounds are observed to form in this system. The hcp lattice constants vary linearly with $\mathrm{Zr}$ concentration (Fig. 1), in good agreement with Vegard's Law. Thus it is indicated that the atomic size difference between $\mathrm{Zr}$ and $\mathrm{Ti}$ atoms is a dominant factor in the changes in structure of $\mathrm{Zr}_{\mathrm{x}} \mathrm{Ti}_{1-\mathrm{x}}$ alloys with changes in $\mathrm{x}$. 


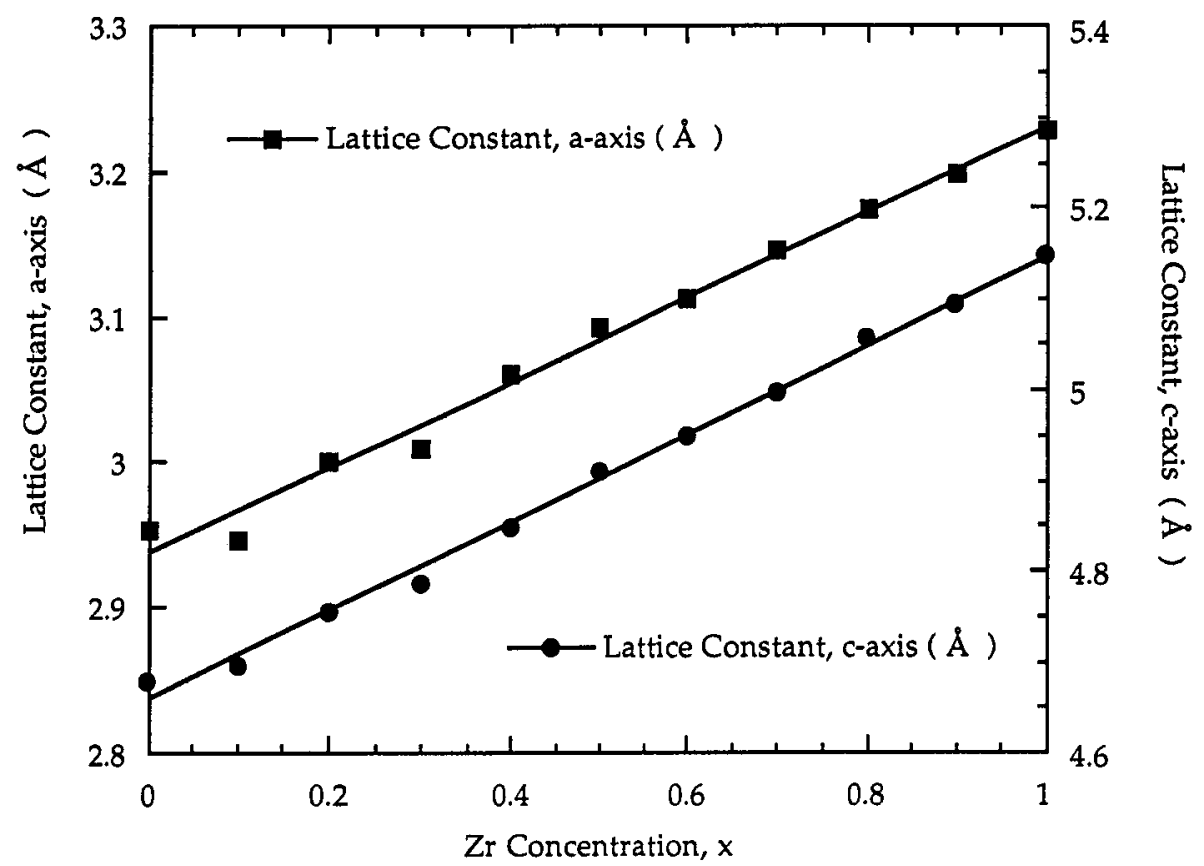

Fig. 1. A plot of the lattice constants as determined by means of $x$-ray diffraction analysis for the hexagonal close packed alloys, $\mathrm{Zr}_{\mathbf{x}} \mathrm{Ti}_{1-\mathrm{x}}$, versus $\mathrm{Zr}$ concentration, $\mathrm{x}$. The values for the a axes, $\mathbf{E}$, are plotted in angstroms on the left vertical axis, while the values for the $c$ axes, $\bullet$, are plotted in angstroms $\left(1 \AA=10^{-10} \mathrm{~m}\right.$ ) on the right vertical axis. Linear fits for each data set are also plotted.

Consideration of some of the parameters for the $\mathrm{Ni}-\mathrm{Zr}_{x} \mathrm{Ti}_{1-x}$ systems that are relevant to the success of solid state amorphization reactions at the expense of the production of crystalline material reveals a number of similarities. Metallic glasses can be produced by means of rapid quenching from the melt in both the $\mathrm{Ni}-\mathrm{Ti}$ and the $\mathrm{Ni}-\mathrm{Zr}$ systems over a wide range of compositions, ranging from roughly 30 to 70 atomic percent $\mathrm{Ni}$, while amorphous $\mathrm{Ni}_{\mathrm{y}}\left(\mathrm{Zr}_{\mathrm{x}} \mathrm{Ti}_{1-\mathrm{x}}\right)_{1-\mathrm{y}}$ alloys have been produced for a number of values of $\mathrm{y}$ over the entire range of values of $x$. These amorphous alloys are relatively stable, and generally exhibit crystallization temperatures which vary monotonically with $\mathrm{x}$ and with $\mathrm{y}$ (refs. 1216). For example, the nearest neighbor distances, as derived by means of the Ehrenfest relation from $x$-ray diffraction profiles of the rapidly quenched alloys, are plotted versus $x$ in Fig. 2. Also plotted in Fig. 2 are the crystallization temperatures of these ${ }^{N i}{ }_{.635}\left(\mathrm{Zr}_{x} \mathrm{Ti}_{1-\mathrm{x}}\right)_{365}$ glassy alloys, as measured by means of differential scanning calorimetry at a constant heating rate of $50 \mathrm{~K} / \mathrm{min}$. Heats of formation of amorphous alloys in the Ni-Ti system are similar to those of the Ni-Zr system, with values of about $40 \mathrm{~kJ} / \mathrm{mol}$ for stoichiometries with 60 atomic percent $\mathrm{Ni}$.

In contrast with the large number of parameters which are observed to be similar for the $\mathrm{Ni}-\mathrm{Zr}_{\mathrm{x}} \mathrm{Ti}_{1-\mathrm{x}}$ systems, the difference in atomic volumes for $\mathrm{Ni}$ and $\mathrm{Zr}$ is significantly greater than for $\mathrm{Ni}$ and $\mathrm{Ti}$. In fact, the change in atomic size as $\mathrm{Zr}$ atoms are substituted for $\mathrm{Ti}$ atoms in the $\mathrm{Zr}_{x} \mathrm{Ti}_{1-\mathrm{x}}$ alloy is an important factor in the course of solid state amorphization reactions in $\mathrm{Ni} / \mathrm{Zr}_{x} \mathrm{Ti}_{1-x}$ composites. Previously, in a study at temperatures near $1000 \mathrm{~K}$ with crystalline elements, $\mathrm{Ni}$ atoms were observed to diffuse one to two orders of magnitude faster in $\alpha-\mathrm{Zr}$ than in $\alpha-\mathrm{Ti}$ (ref. 17). Furthermore, diffusion rates of impurities in liquid quenched amorphous alloys have been correlated with differences in atomic size (refs. 5-7). In fact, while solid state reactions at temperatures below approximately $600 \mathrm{~K}$ in a variety of multilayered $\mathrm{Ni} / \mathrm{Zr}$ composites produce an amorphous alloy, for $\mathrm{Ni} / \mathrm{Ti}$ composites difficulty 


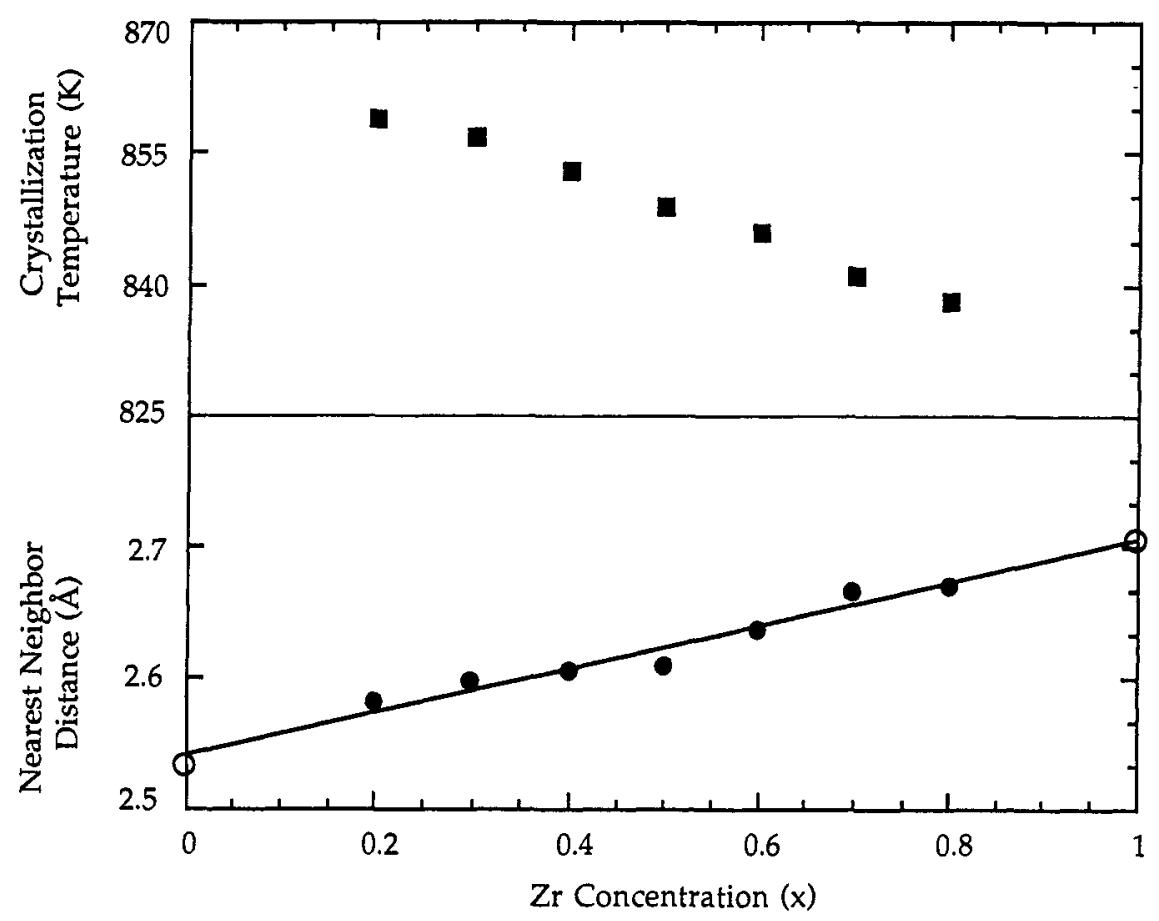

Fig. 2.(a),$O$ Nearest neighbor distances in angstroms (derived by means of the Ehrenfest relation from $x$-ray diffraction profiles of rapidly quenched alloys) as a function of $\mathrm{Zr}$ concentration, $x$. Data represented by $O$ symbols are from refs.15,16. (b) $\square$ The crystallization temperatures of $\mathrm{Ni}_{.635}\left(\mathrm{Zr}_{x} \mathrm{Ti}_{1-\mathrm{x}}\right)_{365}$ glassy alloys, as a function of $\mathrm{x}$, measured by means of DSC at a constant heating rate of $50 \mathrm{~K} / \mathrm{min}$.

is often encountered in the production of amorphous material under similar annealing conditions (refs. 12,13,18). For instance, White et al. (refs. 12,13) found that in mechanically co-deformed $\mathrm{Ni} / \mathrm{Ti}$ composites glassy alloys could be grown by solid state reaction only in composites of relatively high deformation. They observed that the growth of metallic glass was limited to length scales on order of $7 \mathrm{~nm}$ in Ni/Ti composites, in contrast to the case of $\mathrm{Ni} / \mathrm{Zr}$ composites, where growth of amorphous alloy at length scales of up to $100 \mathrm{~nm}$ was observed.

In an effort to observe the dependence of the process of solid state amorphization reactions on atomic size, we examined solid state reactions in $\mathrm{Ni} / \mathrm{Zr}_{\mathrm{x}} \mathrm{Ti}_{1-\mathrm{x}}$ composites as the $\mathrm{Zr}$ concentration was systematically varied. We found a distinct dependence of the solid state reactions on $\mathrm{Zr}$ concentration, even though both the chemical driving force of the formation of amorphous material and the kinetic constraint on the growth of equilibrium compounds were essentially constant for all values of $\mathrm{Zr}$ concentration.

\section{EXPERIMENTAL}

Crystalline alloys were prepared in ingot form by arc-melting $99.97 \%$ pure metals in a Ti-gettered, Ar atmosphere. Pieces of the $\mathrm{Zr}_{\mathbf{x}} \mathrm{Ti}_{1-\mathrm{x}}$ ingots were rolled in stainless steel sheaths into the form of foils. These foils were annealed at a temperature of $823 \mathrm{~K}$ in a Ti gettered, Ar atmosphere. Small pieces of $\mathrm{Ni}_{\mathrm{y}}\left(\mathrm{Zr}_{\mathrm{x}} \mathrm{Ti}_{1-\mathrm{x}}\right)_{1-\mathrm{y}}$ ingots were levitated in high vacuum, and splat quenched in a Bühler piston-piston device at a nominal rate $10^{6} \mathrm{~K} / \mathrm{s}$.

Samples were examined by means of $x$-ray diffraction in both the as-prepared state and after heat treatment, or after splat-quenching. A Rigaku x-ray diffractometer with Ni-filtered, $\mathrm{Cu}$ 
$\mathrm{K}_{\alpha}$ radiation, and/or a GE XRD-6 diffractometer with $\mathrm{Zr}$-filtered, Mo $\mathrm{K}_{\alpha}$ radiation, were utilized to obtain $x$-ray diffraction profiles of samples. Calibrations were performed with NIST powdered Si and also with mica.

Bulk composites were prepared by means of mechanical co-deformation in a rolling mill. $\mathrm{Ni}$ foils were folded over $\mathrm{Zr}_{\mathrm{x}} \mathrm{Ti}_{1-\mathrm{x}}$ foils of similar thicknesses (on order $25 \mu \mathrm{m}$ ), enclosing the $\mathrm{Zr}_{\mathbf{x}} \mathrm{Ti}_{1-\mathrm{x}}$ foils. The composites were placed in rectangular stainless steel sheaths and deformed in a rolling mill. It was observed that the foils cold-welded together to form a composite, sealing the $\mathrm{Zr}_{x} \mathrm{Ti}_{1-x}$ alloy inside the $\mathrm{Ni}$ foil, with no apparent adhesion to the stainless steal sheath. The composite was removed from the deformed stainless steel sheath and the procedure was then repeated (with the deformed sample folded over on itself) a number of times depending on the desired sample configuration (degree of deformation and the thickness of individual layers). Both $\mathrm{Ni} / \mathrm{Ti}$ and $\mathrm{Ni} / \mathrm{Zr}$ composites were examined by means of scanning electron microscopy in order to characterize and compare the individual layer thicknesses in both systems (refs. 12,13). At a given degree of deformation, similar layer thicknesses were observed in composites in both systems. Thus a reasonable, approximate estimate could be made of the interfacial areas in the composites.

Solid state reactions in $\mathrm{Ni} / \mathrm{Zr}_{\mathrm{x}} \mathrm{Ti}_{1-\mathrm{x}}$ composites were initiated as the samples (hermetically sealed in aluminum pans) were heated in a Perkin-Elmer DSC-4 at a constant rate of $20 \mathrm{~K} / \mathrm{min}$. The rate of heat release was measured through the course of a reaction by means of differential scanning calorimetry (DSC). Each anneal was followed by a second anneal (identical thermal conditions) of the same sample; the data from the second scan were subtracted from the data of the first scan (ref. 12).

\section{RESULTS AND DISCUSSION}

$\mathrm{Ni} / \mathrm{Zr}_{\mathbf{x}} \mathrm{Ti}_{1-\mathrm{x}}$ composites were repeatedly examined with $\mathrm{Zr}$ concentrations varied from 0 to 1 in steps of 0.1 . For example, DSC traces for three different values of $x$ are displayed in Fig. 3. It was previously shown that the DSC signal observed below $650 \mathrm{~K}$ for $\mathrm{Ni} / \mathrm{Ti}$ and $\mathrm{Ni} / \mathrm{Zr}$ composites corresponds to the growth of amorphous alloy, whereas at higher temperatures different equilibrium compounds nucleate and grow. Consistent results were obtained by means of $x$-ray diffraction analysis for multilayered $\mathrm{Ni} / \mathrm{Zr}_{x} \mathrm{Ti}_{1-x}$ composites, $0.1<x<0.9$, heated at $20 \mathrm{~K} / \mathrm{min}$ to temperatures below approximately $620 \mathrm{~K}$ and cooled to $320 \mathrm{~K}$. In comparison with $x$-ray diffraction profiles before heating, intensities of Bragg peaks had diminished, and a broad $x$-ray diffraction peak was apparently emerging at diffraction angles similar to those observed for the liquid quenched alloys. For all heating rates between 10 $\mathrm{K} / \mathrm{min}$ and $200 \mathrm{~K} / \mathrm{min}$, and for all values of $\mathrm{x}$, the formation of intermetallic compounds upon heating these composites was observed to be initiated at temperatures above $650 \mathrm{~K}$. This was evidenced by the analysis of $x$-ray diffraction profiles of composites heated to temperatures above $650 \mathrm{~K}$, and cooled to room temperature; and (Fig. 3) by peaks in DSC scans. Given these similar observed rates of growth for crystalline alloys in $\mathrm{Ni} / \mathrm{Zr}_{\mathbf{x}} \mathrm{Ti}_{1-\mathrm{x}}$ composites, one may conclude that the kinetic constraint on the formation of equilibrium compounds is suitably large for all values of $x$ in these diffusion couples.

In order to compare the rate of amorphization of different $\mathrm{Ni} / \mathrm{Zr}_{\mathbf{x}} \mathrm{Ti}_{1-\mathrm{x}}$ composites, we examine reaction rates at relatively low temperatures. In Fig. 4 the heat flow at $575 \mathrm{~K}$ is plotted for a series of $\mathrm{Ni} / \mathrm{Zr}_{\mathbf{x}} \mathrm{Ti}_{1-\mathrm{x}}$ composites, all of which were prepared at a similar, relatively high degree of deformation. This comparison of solid state reactions by means of DSC (cf. Fig. 3) indicates that at lower temperatures $(T<650 \mathrm{~K}$ ) the rate of solid state reaction in the $\mathrm{Ni} / \mathrm{Zr}_{x} \mathrm{Ti}_{1-\mathrm{x}}$ composites is monotonically dependent upon $\mathrm{Zr}$ concentration.

The thickness of amorphous material grown by solid state reactions decreases with decreasing values of $\mathrm{Zr}$ concentration, $x$ in these $\mathrm{Ni} / \mathrm{Zr}_{x} \mathrm{Ti}_{1-x}$ composites. This is despite similar driving forces for solid state amorphization reactions and suitable, similar, kinetic 


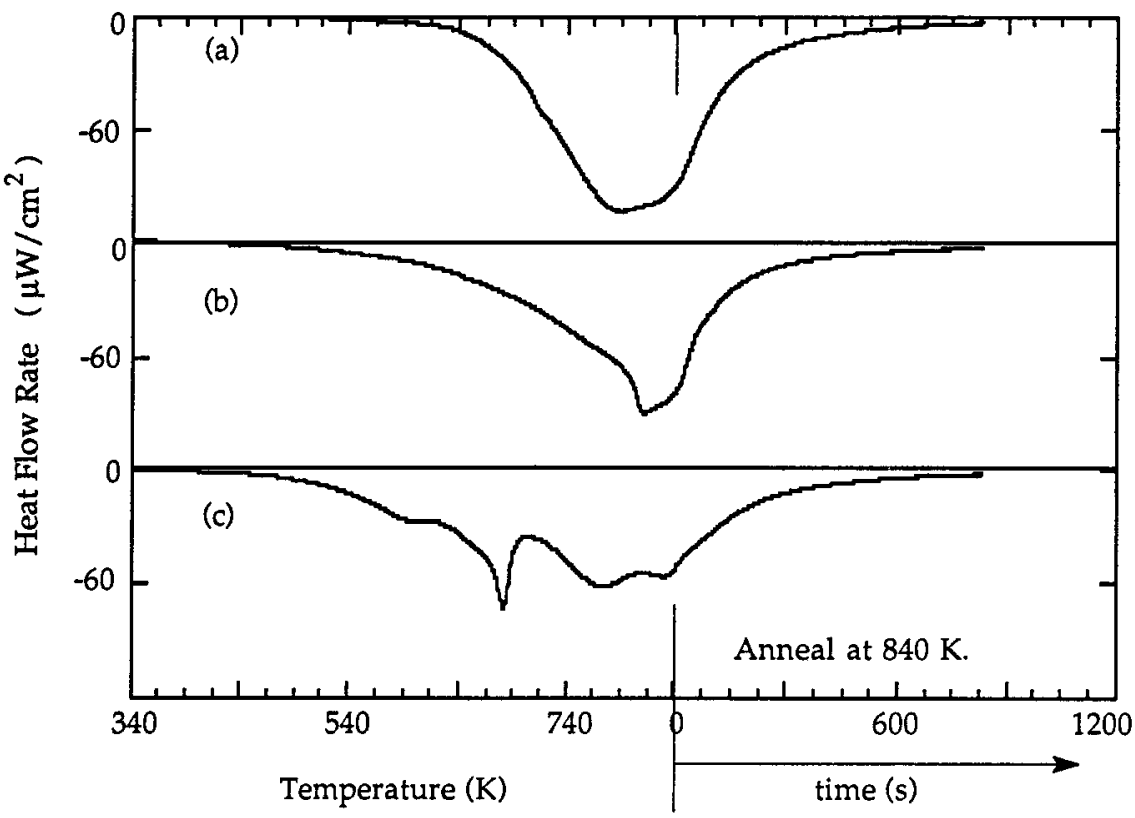

Fig. 3. The heat flow as a function of temperature for a constant scan rate of $20 \mathrm{~K} / \mathrm{min}$, followed by the heat flow as a function of time for an isothermal anneal at $840 \mathrm{~K}$, measured by means of differential scanning calorimetry. The samples were multilayered $\mathrm{Ni} / \mathrm{Zr}_{\mathrm{x}} \mathrm{Ti}_{1-\mathrm{x}}$ composites produced by co-deformation. The initial thicknesses and the deformations were similar for all the composites. The data are for multilayered composites of different $\mathrm{Zr}$ concentration: (a) $\mathrm{Ni} / \mathrm{Zr}_{.1} \mathrm{Ti}_{.9}$ (b) $\mathrm{Ni} / \mathrm{Zr}_{.5} \mathrm{Ti}_{.5}$ (c) $\mathrm{Ni} / \mathrm{Zr}$.

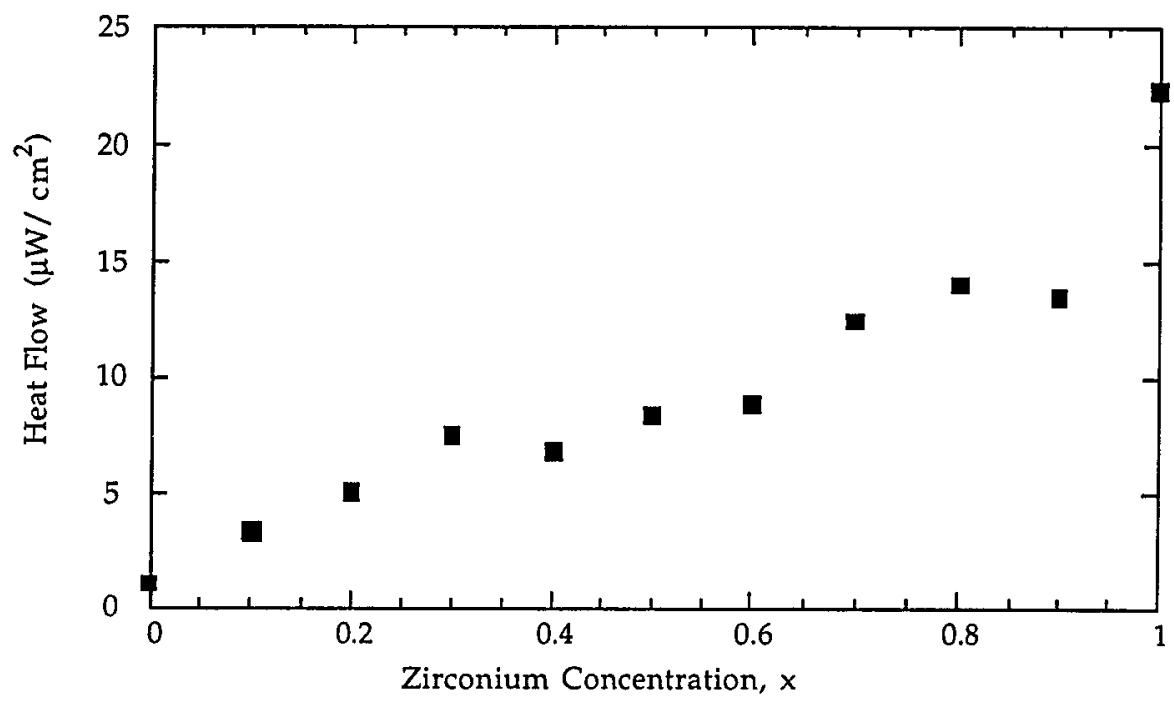

Fig. 4. Heat flow at $575 \mathrm{~K}$ in $\mathrm{Ni} / \mathrm{Zr}_{\mathbf{x}} \mathrm{Ti}_{1-\mathrm{x}}$ multilayered composites heated at a constant rate of $20 \mathrm{~K} / \mathrm{min}$, as a function of $\mathrm{Zr}$ concentration, $x$.

constraints on the formation of equilibrium compounds in all of these systems. The decrease of atomic size of the constituents of the amorphous phase as $x$ is increased apparently limits the mobility of the moving species (i.e. the Ni atoms) in the growing amorphous phase. It has often been stated that a large disparity in the mobility of the atomic constituents in a diffusion couple is one of the requirements for a successful solid state amorphization reaction. The present experiment appears to provide some further evidence in support of this hypothesis. 


\section{Acknowledgements}

We thank K. Unruh and J. Wolanczyk for helpful discussions. Acknowledgement is made to the Donors of The Petroleum Research Fund, administered by the American Chemical Society, for the support of this research.

\section{REFERENCES}

1. R. B. Schwarz and W.L. Johnson, Phys. Rev. Lett 51, 415-418 (1983).

2. W. L. Johnson, Prog. Mater. Sci. 30 81-134 (1986).

3. K. Samwer, Phys. Rep. 161, 1-21 (1988).

4. R. B. Schwarz and W. L. Johnson, I. Less-Common Met. 140, 1-6 (1988).

5. H. Hahn and R. S. Averback, Phys. Rev. B 37, 6537-6541 (1988).

6. H. Hahn, R. S. Averback, and S. J. Rothman, Phys. Rev. B 33, 8825-8828 (1986).

7. K Hoshino, R. S. Averback, H. Hahn, and S. J. Rothman, J. Mater. Res. 3, 55-58 (1988).

8. A. M. Vredenberg, J. F. M. Westendorp, F. W. Saris, N. M. van der Pers and Th. H. de Keijser, I. Mater. Res. 1, 774-780 (1986).

9. E. J. Cotts, W. J. Meng, and W. L. Johnson, Phys. Rev. Lett. 57, 2295-2298 (1986).

10. L. Schultz, in Rapidly Quenched Metals, edited by S. Steeb and H. Warlimont (NorthHolland, Amsterdam, 1984) p.551-553; L. Schultz, in Proceedings of the Sixth International Conference on Liquid and Amorphous Metals, in Z. Phys. Chem., 156-159 (1987).

11. R. J. Highmore, J. E. Evetts, A. L. Greer, R. E. Somekh, Appl. Phys. Lett. 50, 566-568 (1987).

12. B. E. White, Jr., M. E. Patt, and E. J. Cotts, Physical Review B 42,11017-11026 (1990).

13. B. E. White, Jr., M.E. Patt, and E. J. Cotts, I. Appl Phys 68 , 1910-1912 (1990)

14. Z. Altounian, Tu Guo-hua, and J. O. Strom-Olsen, I. Appl. Phys. 54, 3111-3116 (1983).

15. K. H. Buschow, I. Phys. F 13,563-568 (1983).

16. K. H. Buschow, I. Phys. F 14,593-597 (1984).

17. G. M. Hood and R. J. Schultz, Phil. Mag. 26, 329-334 (1972).

18. W. J. Meng, B. Fultz, E. Ma, and W. L. Johnson, Appl. Phys. Lett. 51, 661-663 (1987). 